\title{
PLATAFORMA DIGITAL DE EDUCAÇÃO: A PERCEPÇÃO DOS PROFESSORES
}

\section{DIGITAL PLATFORM IN NETWORK EDUCATION: THE PERCEPTION OF TEACHERS}

\author{
VIANNA, José Antonio ${ }^{1}$ \\ FERREIRA, Telma Antunes Dantas ${ }^{2}$
}

\begin{abstract}
RESUMO
Este estudo avaliativo da implantação de novas tecnologias na escola teve por objetivo analisar a percepção docente sobre o efeito da plataforma digital no contexto escolar. Responderam ao questionário 73 professoras e 22 professores. Os participantes $(70,6 \%)$ consideram que são necessários conhecimentos e habilidades em informática para a utilização da plataforma. Na percepção da maioria dos investigados a plataforma pode melhorar o ensino $(88,5 \%)$, apesar de considerar que a maior parte dos professores da rede estar indiferentes, pouco motivados ou desmotivados para a incorporação da inovação tecnológica no cotidiano escolar. Menos da metade (46,3\%) observam na plataforma um instrumento para diminuição da desigualdade de oportunidades escolares e facilitação da aprendizagem. A infraestrutura deficiente é o principal entrave para utilização do kit nas aulas.
\end{abstract}

Palavras-Chave: Avaliação; Tecnologia Educacional; Inclusão Digital; Desigualdade Educacional.

\begin{abstract}
This evaluation study of the implementation of new technologies in school had to analyze the teacher perception of the effect of the digital platform in the school context. Completed the questionnaire 95 teachers. The participants (70.6\%) believe are necessary knowledge and skills in IT to use the platform. In the perception of most investigated the platform can improve education (88.5\%), although the majority of school teachers are indifferent, poorly motivated or unmotivated to incorporate technological innovation in everyday school life. Less than half (46.3\%) observed in an instrument platform for reducing inequalities in educational opportunities and facilitating learning. The poor infrastructure is a major bottleneck in using the kit in the classroom.
\end{abstract}

KeYwords: Evaluation; Educational Technology; Digital Inclusion; Educational Inequalities.

\footnotetext{
1 Programa de Pós Graduação de Ensino em Educação Básica - PPGEB/UERJ. e-mail: javianna2@hotmail.com

2 Programa de Pós Graduação de Ensino em Educação Básica - PPGEB/UERJ. e-mail: telmaadf@hotmail.com
} 


\section{INTRODUÇÃO}

A impressionante velocidade de produção, recriação e transformação oportunizada pelo mundo digital, já se encontra inserida no universo de novas gerações que têm acesso a este novo universo. No entanto, os avanços tecnológicos parecem próximos de poucos e, ao mesmo tempo, distantes da maioria dos alunos dos cursos regulares no Brasil. Os alunos das camadas populares matriculados em escolas públicas aparecem como os mais impactados pela desigualdade educacional (ALVES; SOARES; XAVIER, 2014; KOLINSKI; ALVES; LANGE, 2013; ENRICA, 2013).

A introdução de novas tecnologias, tais como o ambiente virtual de aprendizagem ou a educação on-line (RAUH, 2011) podem colaborar para minimizar as desigualdades de oportunidades escolares.

Com a perspectiva de aprofundar a compreensão desta temática no meio escolar e fornecer informações para o refinamento das políticas e projetos de intervenção pedagógica, a proposta deste estudo foi avaliar o efeito da plataforma digital de educação no contexto escolar na percepção dos professores dinamizadores nas unidades escolares.

\section{O CONTEXTO TEÓRICO}

Embora a desigualdade no acesso às novas tecnologias, tais como o ambiente virtual de aprendizagem ou na educação on-line (RAUH, 2011) seja uma característica da sociedade brasileira, cabe destacar que o universo virtual de possibilidades infinitas já existe.

Lançar mão das possibilidades do mundo virtual pode significar a melhoria da qualidade da educação a distancia (EaD) ou mesmo da educação presencial. Possibilitar novas aprendizagens em ambiente virtual contribui para a diminuição das desigualdades das oportunidades educacionais (VIANNA, 2009; GIDDENS, 2012). A desigualdade na oferta educacional em grandes metrópoles como a cidade do Rio de Janeiro potencializa a vulnerabilidade dos sujeitos das camadas populares (KOLINSKI; ALVES; LANGE, 2013).

Segundo Giddens (2012) da mesma forma que a imprensa e a cultura de leitura do livro contribuíram para a ascensão da educação moderna, as novas tecnologias da informação (TI) no mundo contemporâneo podem contribuir para transformar o currículo vigente nas instituições de ensino.

Conforme o autor, a economia do conhecimento exige força de trabalho que seja alfabetizada em computação. Silva e Azevedo (2005) observaram que a rejeição dos docentes brasileiros a TI na escola está diminuindo. Segundo Giddens (2012) a maioria dos professores percebe na TI uma ameaça de substituição dos profissionais de educação. Tal fato pode resultar em dificuldades na implantação, difusão e 


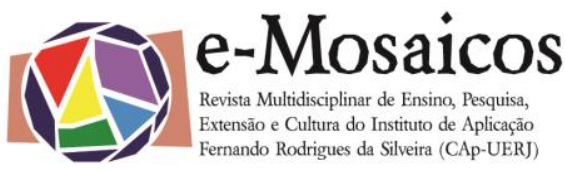

DOI: $10.12957 /$ e-mosaicos.2018.27928

utilização no ambiente escolar, comprometendo os esforços de redes e sistemas de ensino para a democratização do acesso à TI por meio da escola.

Ao envolver-se no mundo virtual, o docente poderá exercer com maior eficiência a mediação entre objetivos, conteúdos e metodologias necessária para estimular no aluno o processo de auto formação continuada.

Silva (2005) sugere como alternativa metodológica a pedagogia tradicional (MIZUKAMI, 1986) a oferta de proposições que admitam a imersão e participação do aluno, que cria, modifica e constrói o conhecimento. Disponibilizar aos atores do processo de ensino-aprendizagem experimentações variadas, conexões em rede e a formulação de problemas em chat, fórum, vídeo e áudio conferência, conexões com outros sites e intertextualidades possibilitam a comparação de vários pontos de vista e a construção de uma perspectiva pessoal.

Na configuração deste novo processo encontramos o professor mediador entre os conteúdos disponibilizados pelas novas tecnologias, cujo papel seria o de orientar e estimular a construção de conhecimentos através das novas redes de relacionamentos virtuais de alunos imersos em um ambiente virtual de aprendizagem.

A demanda do aluno de hoje é ao mesmo tempo real e virtual. É real na medida em que alguns já se encontram inseridos neste mundo digital. A sede discente diz respeito a saberes, competências e habilidades necessárias à sua inserção no mundo digital, com implicações em sua vida acadêmica, social e profissional.

No entanto, este fenômeno transforma-se em virtual, face ao despreparo das instituições educacionais e da ausência de preocupação de parte dos docentes em estar preparado para uma demanda crescente de um grande universo de alunos das classes populares que são analfabetos digitais (GIDDENS, 2012), que chegam à escola sem conhecimentos básicos de informática.

Assim, parece ser necessário ao professor estimular o corpo discente aprender a aprender e resolver os problemas de aprendizagem neste novo contexto cuja eficácia pode estar em ampliar as oportunidades escolares e sociais destes indivíduos.

Segundo Giddens (2012) com o avanço da economia do conhecimento, a educação será ainda mais importante para fornecer aos indivíduos com pouco acesso aos conhecimentos em TI, habilidades e competências que os permitam ser inseridos na nova economia e sair da "pobreza de informações".

Ao que tudo indica, a eficácia da intervenção pedagógica se materializa na prática concreta de seus atores. Portanto, parece ser necessário o estabelecimento de acordos entre as políticas institucionais e as perspectivas dos seus atores (AZANHA, 1991). 
DOI: $10.12957 /$ e-mosaicos.2018.27928

Para tanto, propomos verificar nesta investigação a percepção dos professores dinamizadores da plataforma digital nas unidades escolares na rede municipal de ensino, sobre o efeito desta plataforma no contexto escolar.

Observar os motivos percebidos para a utilização ou não da plataforma como instrumento pedagógico. Verificar a percepção dos benefícios do uso da plataforma na formação dos alunos e na prática pedagógica. Mapear os obstáculos para a instalação e a utilização da plataforma digital.

\section{Metodologia}

Esta investigação se caracteriza por um estudo descritivo exploratório. A amostra desta investigação foi composta por 130 professores da rede municipal de ensino em uma cidade do Rio de Janeiro que se disponibilizaram a atuar como dinamizadores e divulgadores da plataforma digital de educação para outros professores, alunos e toda a comunidade escolar (Mediadores).

Responderam ao questionário semiestruturado elaborado especificamente para esta pesquisa 73 sujeitos do sexo feminino e 22 do sexo masculino. Apenas $13 \%$ dos respondentes tinham idade inferior a 28 anos; 34\% apresentaram idade acima de 43 anos de idade - 19\% estavam entre 28 a 32 anos, $18 \%$ entre 33 e 37 anos e $16 \%$ entre 38 e 42 anos de idade.

O questionário auto administrado procurou ampliar e aprofundar a compreensão das racionalidades dos sujeitos investigados na perspectiva de Max Weber (DEVINE, 2010).

O estabelecimento de categorias para análise precedeu a triangulação e interpretação dos resultados - respeitando a capacidade de verbalização dos participantes (THIOLLENT, 1980), a fim de obter hipóteses a partir de observações e da indução.

O presente trabalho atendeu as normas para a realização de pesquisa em seres humanos, Resolução 466/12 (BRASIL, 2012) e da Resolução de Helsinki (WMA, 2008). Previamente foram explicados para os entrevistados os objetivos do estudo, o sigilo de informações e a disponibilidade de participação por meio do Termo de Consentimento Livre e Esclarecido. A entidade na qual foi executada a pesquisa, recebeu uma Carta de Informação à Instituição, com o qual tomou conhecimento das condições de realização da mesma.

\section{RESULTADOS: NÍVEL DE FORMAÇÃO INICIAL E FORMAÇÃO CONTINUADA DOS PARTICIPANTES}

A função predominante na rede municipal de ensino, exercida pelos participantes no estudo era a de Professor I (58\% dos professores licenciados com atuação no segundo segmento do ensino fundamental), enquanto $34 \%$ atuavam como professor II (professores regentes no primeiro segmento no ensino 
DOI: $10.12957 /$ e-mosaicos.2018.27928

fundamental) e 1 coordenador pedagógico - 62\% concluíram cursos de formação continuada nos últimos cinco anos - $9 \%$ nos últimos 4 a 5 anos, 35\% nos últimos 3 a 1 anos e $28 \%$ nos últimos 11 meses. Os cursos informados foram especialização $(52,6 \%)$, mestrado $(7,4 \%)$ e doutorado $(3,2 \%)$.

Embora a proposta da plataforma enfatize que não é necessária qualquer capacitação para a sua utilização quase a metade dos respondentes (42\%) informou que participaram de alguma capacitação para trabalhar com a plataforma digital. A maioria (55\%) informou não ter tido qualquer capacitação, enquanto 3 indivíduos apresentaram outras justificativas.

A crença de que são necessários conhecimentos e habilidades prévios em tecnologia da informação para professor utilizar a plataforma digital foi confirmada por $70,6 \%$ dos respondentes. Segundo informou o Mediador 49, são necessários saberes e habilidades para lidar inclusive com situações relacionadas à infraestrutura peculiar a cada escola.

Ter conhecimento do uso do computador e, principalmente, da montagem e projeção em sala de aula. Na escola que trabalho, por exemplo, foram instalados os kits em todas as salas, mas os alunos arrebentaram os fios e quebraram alguns aparelhos. Assim, para utilizar a Educopédia, preciso pegar um data show na Direção e montar tudo dentro de sala. Dá um trabalho e é preciso saber conectar os fios corretamente. Confesso também que alguns professores, inclusive eu, têm receio de que algum aluno tropece em um fio, ou mesmo, por dolo, acabe quebrando algum aparelho (sic) (Mediador 49).

Esta percepção aparece aliada à necessidade de valores e atitudes que possam romper com o paradigma do ensino tradicional. Verifica-se a ênfase em professores que tenham compromisso, interesse e boa vontade $(15,1 \%)$, que não tenham medo do "novo" (14,3\%). Um professor que seja possuidor de uma nova consciência.

É preciso que o professor perca o medo do novo, que tente se adaptar as mudanças principalmente tecnológicas. Percebo que muitos não sabem e tem medo de usar o computador. A presença de alguém constantemente na escola disposto a tirar as dúvidas e auxiliar na utilização da ferramenta ajuda bastante. No caso da minha escola professoras que mal sabiam ligar o computador passaram a usar os equipamentos por saberem que podiam contar comigo, embaixadora. Somente as capacitações oferecidas até o momento não são suficientes para convencer os professores a usar (sic.) (Mediador 23). 
Primeiramente a vontade de trabalhar de maneira diferente e visualizar que os mesmos conteúdos que seriam trabalhados de maneira tradicional podem ser colocados de um modo bem mais interessante (Mediador 55).

Ao considerar que $55,8 \%$ dos investigados (53 sujeitos) acreditam que os professores estão indiferentes à utilização da plataforma, $20 \%$ pouco motivados e $7 \%$ desmotivados, deve-se ter em conta que o trabalho de sensibilização e de informação junto aos professores da rede deve ser mais enfatizado, para que a maioria esteja tão motivada quanto a percepção dos $18 \%$ restantes - 12 investigados informaram que os professores estão motivados e 4 muito motivados.

Há de se considerar que romper com a tradição cultural e construir novos valores, atitudes e comportamentos não é tão rápido quanto os avanços tecnológicos o são. Ao considerar os argumentos de Gidenns (2012) de que os professores temem ser substituídos pela TI, o desafio das propostas institucionais de que o docente aprenda integrar a TI na sala de aula pode não ocorrer tão rapidamente quanto os entusiastas da TI poderiam prever.

\section{A RELAÇÃO DA PLATAFORMA DIGITAL COM AS OPORTUNIDADES ESCOLARES E SOCIAIS}

A maior parte dos investigados $(88,5 \%)$ acredita que a plataforma digital irá melhorar o processo de ensino-aprendizagem na rede de ensino. $62,2 \%$ dos participantes argumentam que as escolas que a utilizam serão beneficiadas, enquanto $5,2 \%$ tem a percepção de que a plataforma digital não propicia qualquer benefício (Tabela 1).

\section{Tabela 1 - 0 efeito da plataforma digital na rede municipal de ensino}

\begin{tabular}{|c|c|c|}
\hline Opções & Freq. & $\%$ \\
\hline Vai piorar o processo de ensino em toda a rede & 1 & 1 \\
\hline $\begin{array}{l}\text { Irá piorar o processo de ensino nas escolas que utilizarem a } \\
\text { plataforma }\end{array}$ & & \\
\hline Não irá alterar o processo de ensino & 3 & 3,2 \\
\hline $\begin{array}{l}\text { Irá melhorar o processo de ensino nas escolas que utilizarem a } \\
\text { plataforma }\end{array}$ & 59 & 62,2 \\
\hline Irá melhorar o processo de ensino em toda a rede & 25 & 26,3 \\
\hline Não será utilizada & 1 & 1 \\
\hline Outros & 6 & 6,3 \\
\hline Total & 95 & 100 \\
\hline
\end{tabular}

Fonte: Elaborado pelos autores 
DOI: $10.12957 /$ e-mosaicos.2018.27928

Inclusão digital e igualdade de oportunidades escolares $(46,3 \%)$ foram destacadas como os aspectos que mais se encaixam no processo de aprendizagem por meio da plataforma. Em particular a versatilidade $(31,6 \%)$ foi apontada como um fator relevante da plataforma para o processo de ensino. Embora 4,2\% dos respondentes considerem a plataforma superficial (Tabela 2).

Tabela 2 - A relação da plataforma digital com o processo de ensino

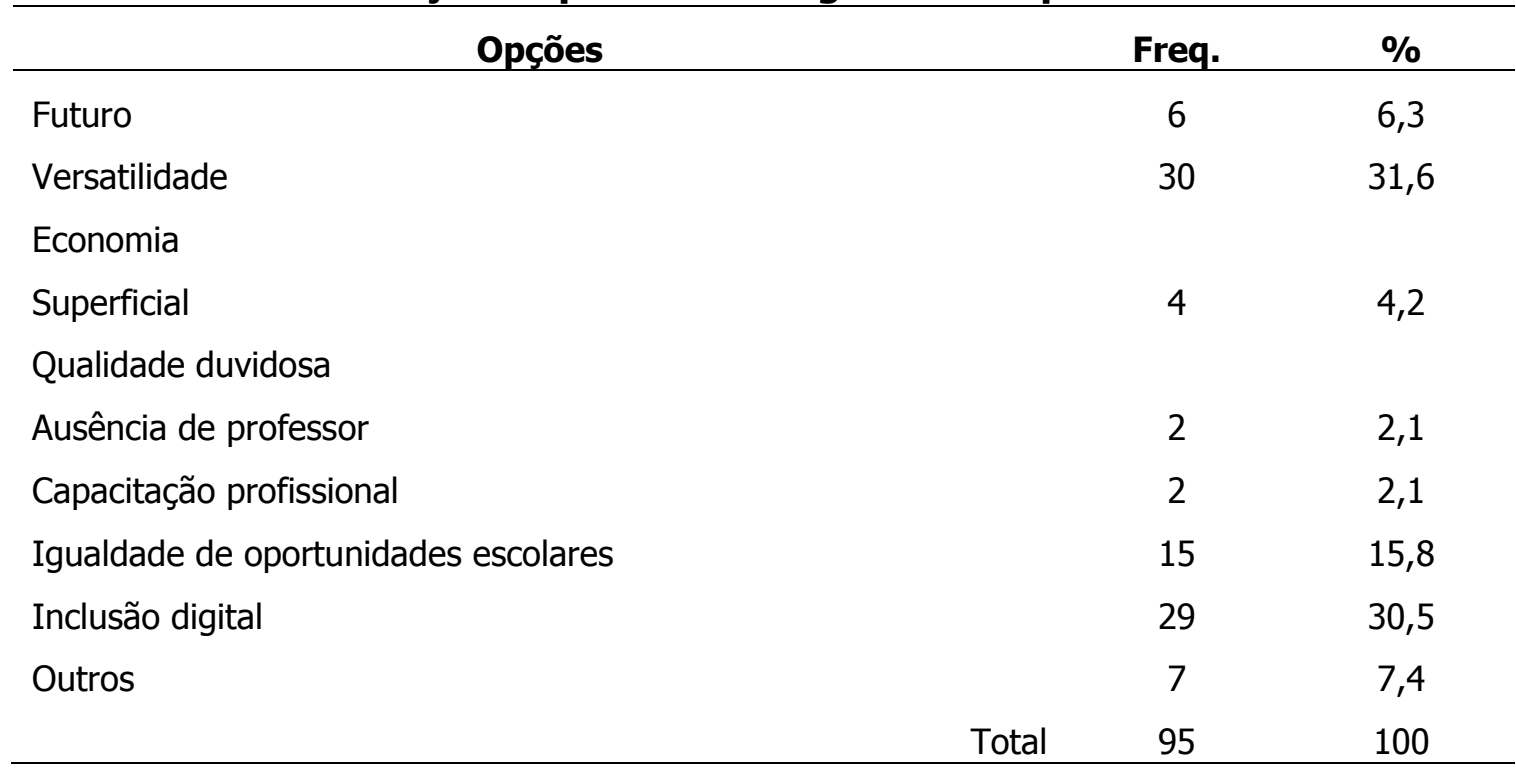

Fonte: Elaborado pelos autores.

Observações fortuitas indicam que os sujeitos das camadas populares parecem perceber nas experiências cotidianas e nos exemplos de parentes e conhecidos próximos, que a educação escolar não tem se prestado a corrigir as desigualdades devidas à origem social. Em estudo macro social Boudon (1981) notou que o pressuposto de que ao aumento das oportunidades industriais, corresponderia ao aumento das oportunidades escolares e sociais, não se confirmou. Segundo o autor, não existe relação causal acerca do impacto do desenvolvimento do sistema escolar e a diminuição das desigualdades das oportunidades escolares, sobre a mobilidade social.

Os indivíduos parecem perceber a existência de uma incongruência entre as estruturas educativas e as estruturas sociais. A estrutura social pode ser considerada como condicionante da inserção sócio-profissional dos indivíduos. Embora o nível de instrução possa ter uma influência importante na posição social do sujeito, este pode ter sua mobilidade restringida pelas oportunidades sociais, econômicas ou pelas limitações do mercado de trabalho, indicando pequena influência do nível de instrução sobre a mobilidade social.

A escola, a herança cultural, o meio social e a estrutura das relações familiares parecem exercer influência nas atitudes e comportamentos dos indivíduos em 


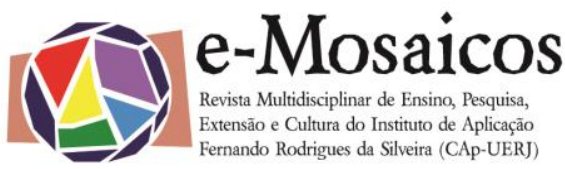

DOI: $10.12957 /$ e-mosaicos.2018.27928

relação às suas expectativas de êxito escolar e social. Os indivíduos se comportam de modo a escolher a combinação custo - risco - benefício mais útil, o que pode representar em investir mais ou menos na educação escolar.

Assim, percebe-se que no Brasil, ao lado de uma economia moderna, existem milhões de indivíduos excluídos dos benefícios e direitos sociais, entre os quais o acesso à tecnologia e a informação. Este fenômeno reforça a baixa qualificação e educação dos indivíduos que integram a base da pirâmide social, favorece a reposição do pobre no meio da pobreza e dificulta a mobilidade social (PASTORE; SILVA, 2000).

A educação de qualidade passou a ser um instrumento para ter êxito num mercado mais exigente. Portanto, a redução da desigualdade depende de investimentos na educação das crianças de hoje, para aumentar os anos de escolaridade e para que estas possam ocupar postos de trabalho que exijam melhor qualificação quando forem adultos.

Considerada como base das transformações sociais necessárias para a diminuição da desigualdade social, a educação brasileira ainda está longe de ser um instrumento para tanto. Segundo Pastore e Silva (2000), a educação é um instrumento importante, mas de efeito demorado. Os avanços na educação ao longo do séc. $X X$ foram muito pequenos.

Em estudo realizado com chefes de família na faixa etária de 25 a 64 anos, para pessoas nascidas na década de 1930 a escolaridade média era de 3 anos. Os anos de escolaridade subiram lentamente, até chegar a 5,6 anos para quem nasceu na década de 1970 mantendo esta regularidade. Os homens que nasceram em 1998, terão nove anos de escolaridade apenas em 2020, o que é muito pouco quando comparado a países que possuem tempo de escolaridade bem superiores (PASTORE; SILVA, 2000).

Os investimentos em educação on-line crescem em diversos países para atender às necessidades do mundo contemporâneo, que sinalizam para práticas pedagógicas coerentes com as necessidades atuais (ARAÚJO, 2007). Para atender as novas perspectivas Araújo (2007) sugere a articulação das novas tecnologias, as concepções de conhecimento e de educação envolvidas no processo de ensino.

A utilização de meios digitais de educação implica na modificação de procedimentos pedagógicos relacionados à aprendizagem dos alunos (MELO; ROCHA; MERCADO, 2008) em processo de empoderamento destes (PESCE; BRUNO, 2015). Assim a formação inicial e continuada dos professores deve contemplar as competências necessárias para a construção e a ampliação das condições didáticopedagógicas facilitadoras da aprendizagem.

Reconhecer, capturar e explicar os processos pedagógicos decorrentes da interação entre as novas tecnologias de comunicação e espaços on-line estão entre as competências necessárias ao professor imerso no novo contexto educacional (TURVEY, 2010). Refletir sobre o desenvolvimento de sua própria linha pedagógica e 
DOI: $10.12957 /$ e-mosaicos.2018.27928

profissional, sobre os conhecimentos necessários à prática e a compreensão em relação à aprendizagem em ambiente eletrônico e virtual, são prerrogativas da atuação docente.

\section{COMPETÊNCIAS E HABILIDADES DO PROFESSOR EM TI}

Os investigados acreditam que os professores da rede de ensino têm competência técnica para utilizar a plataforma (55\%) - embora $26 \%$ disseram que não e $19 \%$ não opinaram.

Questionados então, por que os professores não fazem uso da plataforma digital, os informantes responderam que a precariedade da infraestrutura da escola $(51,3 \%)$ e a falta de conhecimentos e habilidades em TI $(19,5 \%)$ são os motivos principais.

Os professores não a usam, porque ela não chega até a escola. É interessante notar, que a Educopédia é ótima, para o resto do mundo, mas para os alunos da Rede ainda é uma utopia. Não temos internet que suporte a plataforma, eu e meus alunos já ficamos frustrados diversas vezes, porque não dá pra baixar as aulas, elas simplesmente não conseguem carregar. Sem falar que o kit não foi instalado, então temos que ficar carregando aquele peso pra cima e prá baixo a toda hora (Mediador 33.

Geralmente, a falta de infraestrutura da escola é o grande dificultador do uso de educopédia pelos professores da escola em que trabalho. Até o final de 2012, o acesso a internet era bastante difícil na escola, podendo dizer até impossível por semanas. Os kits ainda hoje não estam $100 \%$ instalados nas salas de aula. Então, os mais motivados pediam o projetor e o netbook da escola, ligavam as suas próprias caixinhas amplificadoras de som e fazem uso do seu próprio moden 3G para acessar a plataforma durante a aula. Hoje já existe acesso a internet na escola, mas ainda nos falta os kits instalados nas salas. Montar todo o kit para só depois começar a aula demanda muito tempo de um tempo de 50 minutos, sendo assim, muitos colegas evitam utilizar a plataforma em aula por conta disso" (sic.) (Mediador 48).

A precariedade na infraestrutura educacional em escolas públicas é um dos aspectos que colaboram para ampliar a desigualdade no acesso à informação entre ricos e pobres, contribuindo para reforçar a "pobreza de informação" (GIDDENS, 2012). 
DOI: $10.12957 /$ e-mosaicos.2018.27928

Por outro lado, os professores também resistem para utilizar novas tecnologias educacionais. Segundo Lago Martinez (2015) diretores e professores encaram a implantação de novas tecnologias na escola com reservas.

Nesta investigação foram observados: a falta de interesse pessoal dos professores $(14,2 \%)$; a crítica exercida por aqueles à qualidade da organização dos conteúdos da plataforma (11,5\%); e o desinteresse e mau comportamento dos alunos $(3,5 \%)$, foram apontados pelos respondentes como motivos para que os professores regentes não utilizem a plataforma digital.

A representação de que a máquina pode vir a substituir o homem também apareceu na fala dos participantes no estudo que perceberam o receio de docentes serem substituídos no processo de ensino - dados que confirmam os argumentos de Giddens (2012).

Muitos professores possuem o receio da ferramenta, futuramente, substituir o professor em sala de aula. Além disso, muitos informaram que, apesar da ajuda que forneço a eles como embaixadora em minha escola, seria necessária uma capacitação para melhor manuseio da plataforma. Além disso, alguns informaram que alguns conteúdos apresentam-se de forma incompleta, sendo necessário o uso do quadro para complementação do assunto (sic.) - (Mediador 24).

Segundo Junqueira (2012) o posicionamento do professor frente à TI em sala de aula é reflexo da história do desenvolvimento da tecnologia na sociedade na construção de identidades e subjetividades que têm forte influência na formação e nas vivências dos professores. Conforme o autor cabe aos gestores e idealizadores das políticas educacionais a compreensão das complexidades e contradições do professor como ator social para que as intervenções sejam mais eficazes. Assim, melhor remuneração, financiamento para equipamentos pessoais e capacitação podem ser estímulos ao uso cotidiano de novas tecnologias.

\section{A INFLUÊNCIA DA EQUIPE DE GESTÃO ESCOLAR}

Segundo os participantes a equipe gestora das unidades escolares atribui muita importância à utilização do kit da plataforma digital nas salas de aulas $(45,7 \%)$ - 20,6\% acha importante, enquanto 20,6\% informaram que a direção é indiferente, credita pouca importância (9\%) ou nenhuma importância (3\%).

Na percepção dos entrevistados os gestores das escolas procuram oferecer apoio ao professor que deseja utilizar a plataforma (77\%), mas o maior entrave à inserção da plataforma nas aulas regulares são as dificuldades encontradas na infraestrutura das Unidades Escolares (71\%) que não estão preparadas para que o professor possa fazer uso dos equipamentos e da plataforma. 
e-Mosaicos - Revista Multidisciplinar de Ensino, Pesquisa, Extensão e Cultura do Instituto de Aplicação Fernando Rodrigues da Silveira (CAp-UERJ)

V. 7 - N. 14 - ABRIL 2018 - ISSN: 2316-9303

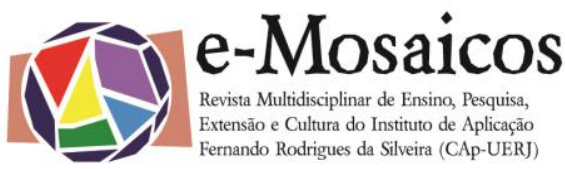

DOI: $10.12957 /$ e-mosaicos.2018.27928

Segundo Avidov-Ungar e Eshet-Alkakay (2011) a implantação de tecnologias inovadoras na escola implica em mudanças pedagógicas, tecnológicas e de gestão na cultura escolar. As novas ferramentas tecnológicas devem ser desafiadoras das práticas pedagógicas dos professores ao mesmo tempo em que devem ajudar aos docentes integrar os novos métodos e pedagogias em seu trabalho (HAMALAINEN; HAKKINEN, 2010).

As plataformas digitais para o ensino, a aprendizagem e a gestão escolar parecem ser dependentes dos valores da equipe de gestão e dos professores que tomarão parte no novo processo. Estes atores podem contribuir positiva ou negativamente na adoção da nova metodologia, reforçando ou não a crença de que as tecnologias educacionais podem ajudar a melhorar 0 ensino existente $\mathrm{e}$ desenvolver pedagogias alternativas (AVIDOV-UNGAR, 2010).

A introdução de recursos tecnológicos na educação reforça a perspectiva de uma intervenção multiprofissional e interdisciplinar. A plataforma digital implica em novas formas didáticas condizentes com a contemporaneidade que as novas tecnologias apresentam (FRANÇA, 2009).

Segundo França (2009) os recursos do Ambiente Virtual de Aprendizagem (AVA) como a plataforma digital em questão podem ser facilitadores da aprendizagem ao otimizar o tempo - que deixa de ser do professor e passa a ser do aluno, o espaço - que ultrapassa os limites da sala de aula e a compreensão - que aprofunda e amplia a resolução de problemas complexos. Estes recursos devem ser utilizados para facilitar o processo de ensino-aprendizagem e possibilitar a produção do conhecimento, ultrapassando o simples acúmulo de informações.

A facilidade de acesso à variedade e quantidade de informações propiciadas pelas novas tecnologias implica em que o professor incentive os alunos a saberem perguntar, selecionar questões importantes, a ter critérios de escolha, de avaliação e comparar textos com opiniões diferentes com a finalidade de elaborar sínteses (MORAN, 2009).

Segundo Moran (2000) a eficácia na implantação das novas tecnologias na escola passa em equilibrar o planejamento institucional e os recursos humanos. Segundo o autor a equipe de gestão da unidade escolar pode contribuir ou não para alavancar a implantação da plataforma.

O docente pode colaborar neste processo ao adotar procedimentos de ensino que facilitem a adaptação dos programas às necessidades dos alunos. $O$ papel do professor deve ser de mediador e organizador de processos de aprendizagem a fim de ajudar os alunos interpretar os dados, relacionando e contrastando as informações selecionadas e contextualizando-as (MORAN, 2000).

A sala de aula deve ser um espaço de investigação adaptada aos diversos ritmos de aprendizagem. Sob esta perspectiva o professor deve iniciar o processo de busca e descoberta apresentando o cenário, sínteses, o estado da arte, a questão ou o tema a ser pesquisado. A seguir os alunos procuram novas informações para 
DOI: $10.12957 /$ e-mosaicos.2018.27928

cercar o problema, desenvolver uma experiência e avançar no campo desconhecido. A síntese do material coletado deve ser lido e discutido com todo o grupo. 0 material mais consistente é enriquecido pelo professor com novas contribuições de pesquisa, questionado, relacionado com o tema para ser utilizado na aula seguinte.

Moran (2000) sugere que os temas principais da disciplina devem ser tratados coletivamente, enquanto os pontos secundários trabalhados individualmente ou em pequenos grupos. "O professor procura ajudar a contextualizar, a ampliar o universo pelos alunos, a problematizar, a descobrir novos significados no conjunto das informações trazidas" (p.140).

\section{A RELAÇÃO PROFESSOR-ALUNO-AMBIENTE VIRTUAL}

Segundo a percepção dos embaixadores que participaram no estudo motivar o aluno $(47 \%)$, diversificar as estratégias de ensino $(16,2 \%)$, tornar a aula mais dinâmica $(14,9 \%)$, inovação tecnológica para melhoria das aulas $(13,5 \%)$, a ludicidade nas aulas $(6,7 \%)$ e oferecer aos alunos da rede igualdade de oportunidades escolares às oferecidas aos alunos da rede particular $(1,4 \%)$, são os motivos que os professores têm para utilizarem a plataforma digital.

O bacana da educopédia é ela também pode ser uma ferramenta que estimula a autonomia de estudo do aluno que pode utilizar a plataforma para estudar em casa, na escola ou na lan house. Uma vez que o aluno pode acessa-la e aproveitar as diversas atividades extras disponíveis como o jogo zuum ou a educoteca mesmo sem o suporte do professor na sua utilização. $E$, ainda a possibilidade de acessar novamente as aulas que já foram ministradas para revisar. Finalmente, o acesso a educopedia em sala de aula bem como outras fontes digitais confiáveis em sala de aula, geram possibilidade de equiparar as salas de aula da rede municipal do $\mathrm{RJ}$ as salas de aulas de muitos colégios particulares que já fazem uso de quadros interativos (smartboard) nas suas salas de aula. Gerando assim, oportunidades parecidas para alunos de escola pública e particular. Acredito que tanto a EDUCOPÉDIA, bem como a implantação do ESCOLA 3.0, representam uma grande melhoria na infraestrutura e a qualidade do ensino no município do Rio (sic.) - (Mediador 42).

Imerso neste contexto e agente neste processo, a percepção e atitudes do professor desempenha papel importante para o sucesso ou o fracasso para a implantação de projetos com novas tecnologias. A diferença nos valores pode criar a ineficácia e prejudicar a expansão da implantação das novas tecnologias.

Uma alternativa para otimizar a implantação das novas tecnologias está na formação continuada de professores e gestores. Oliveira, Rego e Villardi (2007) observaram na percepção de professores que o uso da internet como espaço virtual 


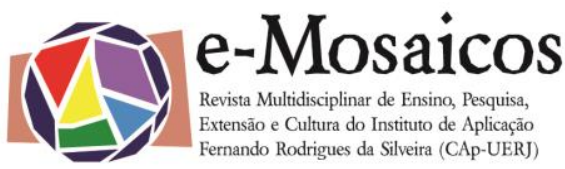

DOI: $10.12957 /$ e-mosaicos.2018.27928

de aprendizagem colabora na interação dos interlocutores e na discussão de ideias. Favorece a capacidade de pensar categorialmente, utilizar recursos linguísticos, autorregular o comportamento e a aprendizagem, potencializar algumas áreas cognitivas e criar novas formas de convívio social, afetivo e cultural.

Além de propiciar novas experiências de aprendizagem, o ambiente virtual propiciado pela plataforma digital retira os professores do centro do processo de ensino-aprendizagem e oportuniza a interação e aprendizagem mútua (PAIVA, 2010). Este novo ambiente possibilita a participação ativa dos alunos, possibilita a assimilação ativa de conteúdos mais atraentes e facilitam a aprendizagem ( $\mathrm{XU}$; PARK; BAEK, 2011).

Pesquisa realizada em escolas na Malásia sobre a influência de ambientes virtuais de aprendizagem na formação de estudantes verificou a melhoria do pensamento criativo na construção do conhecimento (SULTAN; WOODS; KOO, 2011).

Ao que tudo indica para superar a resistência às mudanças na cultura escolar tradicional, o professor deve procurar estabelecer os acordos com os interesses discentes, que passa por compreender as razões para o baixo envolvimento ou a eventual insatisfação dos discentes com a experiência de aprendizagem em ambiente virtual (LIAW, 2008).

O desenvolvimento de habilidades e competências sociais e cognitivas dos jovens que jogam games é destacado por Santaella (2012), que ao comparar os games com os jogos educacionais argumenta que estes últimos carecem de maior ludicidade, sem a qual, são pouco desafiadores e motivantes.

Segundo Avalos (2008) a presença das tecnologias da informação e da comunicação na vida diária das pessoas ressalta a importância da educação digital como uma ferramenta necessária aos alunos nos anos iniciais do ensino fundamental, tanto para melhorar o processamento de informações quanto para o manejo técnico das mesmas. Investigações recentes sugerem que o ambiente virtual pode ser utilizado em sala de aula como um meio para a melhoria da escrita (XU; PARK; BAEK, 2011), ganho no na visualização espacial, maior precisão na rotação mental e melhor desempenho na solução de tarefa de desenho ortográfico, o que sugerem melhoria na performance cognitiva (SAMSUDIN; RAFI; HANIF, 2011).

\section{CONCLUSÕES E RECOMENDAÇõES}

Ao analisar o efeito da implantação da plataforma digital em escolas da rede pública de ensino verificamos que a velocidade dos avanços tecnológicos contemporâneos presentes no mundo digital tem alcançado de forma desigual os cidadãos brasileiros, entre os quais os professores. Os docentes se apresentam inseguros, receosos e desconfiados com a introdução das novas tecnologias educacionais por não dominarem conhecimentos e habilidades mínimas em TI para o seu manuseio e utilização. Assim, os esforços para romper com o paradigma da 
DOI: $10.12957 /$ e-mosaicos.2018.27928

educação tradicional, enriquecer o processo de ensino com a introdução de novas tecnologias educacionais e oportunizar aos sujeitos das camadas populares 0 acesso a bens culturais e educacionais que outras camadas sociais usufruem, podem ter os seus efeitos comprometidos ou minimizados.

A transformação da atitude e da prática docente poderá ocorrer se os docentes tiverem mais oportunidades de vivenciarem o ambiente virtual de aprendizagem. Em função de hábitos estabelecidos, da acomodação do profissional, do excesso de atribuições ou de outros impedimentos reais ou imaginários, parece ser necessário que esta experimentação ocorra no tempo-espaço escolar. A instituição de ensino deve perceber que a ampliação do tempo disponível sob a orientação e assessoria de um professor mais experiente (Mediador) não se trata de perda, mas de uma vantagem inestimável para a melhoria progressiva no processo de ensino.

Resolvidas as falhas na infraestrutura da Unidade Escolar, o desenvolvimento de competências e habilidades em TI e a sua ambientação com a plataforma digital, permitirá ao professor exercer com maior eficiência a mediação entre objetivos, conteúdos e metodologias necessária para estimular no aluno o processo de auto formação continuada.

\section{REFERÊNCIAS}

AIDOV-UNGAR, O. "Islans of Innovation" or "compreensive innovation". Assimilating educational technology in teaching, and management: a case study of school networks in Israel. Interdisciplinary Journal of E-Learning and Learning Objects. v.6, 2010.

AIDOV-UNGAR, O.; ESHET-ALKAKAY, Y. Theachers in a world of change: teacher's knowledge and attitudes towards the implementation of innovative technologies in schools. Interdisciplinary Journal of E-Learning and Learning Objects. v.7, 2011.

ARAÚJO SILVA, M. M. O pensamento complexo: desafios emergentes para a educação on-line. Revista Brasileira de Educação. Vol12, 36, 2007, p.515.

ALVES, Maria Teresa Gonzaga; SOARES, José Francisco; XAVIER, Flavia Pereira. Índice socioeconômico das escolas de educação básica brasileiras. Ensaio: aval.pol.públ.Educ., Rio de Janeiro, v. 22, n. 84, p. 671-703, set. 2014. Disponível em <http://www.scielo.br/scielo.php?script=sci_arttext\&pid=S0104$40362014000300005 \& \mathrm{lng}=\mathrm{pt} \& \mathrm{nrm}=\mathrm{iso}>$. Acesso em 19 jun. 2015. http://dx.doi.org/10.1590/S0104-40362014000300005.

AVALOS, G. G. El uso de la tecnologia de la informacion y la comunicacion y el dieno curricular. In: Educacion, v. 32, n. 1, jan-june, 2008. 
DOI: $10.12957 /$ e-mosaicos.2018.27928

AZANHA, J. M. P. Cultura escolar brasileira: Um programa de pesquisas. In: Revista USP, dez-jan-fev, 1990 / 1991.

BABBIE, E. Métodos de pesquisa de survey. Belo Horizonte: Ed. UFMG, 1999.

CONSELHO NACIONAL DE SAÚDE (BRASIL). Resolução CNS n 466, de 12 de dezembro de 2012. Brasília, 2012. Disponível em: http://www.conselho. saude.gov.br/web_comissoes/conep/index.html. Acesso em 19 jun. 2015.

ERNICA, M. Desigualdades educacionais no espaço urbano: o caso de Teresina. In: Rev. Bras. Educ., Rio de Janeiro , v. 18, n. 54, p. 523-788, set. 2013 . Disponível em <http://www.scielo.br/scielo.php?script=sci_arttext\&pid=S1413$24782013000300002 \&$ Ing $=$ pt\&nrm $=$ iso $>$. Acesso em 19 jun. 2015. http://dx.doi.org/10.1590/S1413-24782013000300002.

FRANÇA, G. Os ambientes de aprendizagem na época da hipermídia e da Educação a distância. In: Perspectivas em Ciência da Informação. v.14, no1, p.55-65, jan/abr, 2009.

GIDDENS, A. Sociologia. 6ed. Porto Alegre: Penso, 2012.

GOMES, M. J.; COUTINHO, C. P.; GUIMARÃES, F. M. S.; CASA-NOVA, M. J.; CAIRES, S. Educação à distância e e-learning na Universidade do Minho: análise das percepções, concepções e práticas docentes no Instituto de Educação. 2011.

JUNQUEIRA, E. O problema da implantação das tecnologias digitais nas escolas e das identidades profissionais dos professores: uma análise sócio-histórica. In: Revista Teias, v.13, no 30, 291-310, set-dez 2012.

KERAMATI, A; AFSHARI-MOFRAD, M.; KAMRANI, A. The role of readiness factors in E-learning outcomes: Na empirical study. In: Computers \& Education. v. 57, n.3, 2011, p.1919-1929.

KOLINSKY, M. C.; ALVES, F.; LANGE, W. J. Desigualdades educacionais em contextos urbanos: um estudo da geografia de oportunidades educacionais na cidade do Rio de Janeiro. In: Educação \& Sociedade. [online], vol.34, n.125, p. 1175-1202, 2013. Disponível em: <http://www.scielo.br/scielo.php?script=sci_arttext\&pid=S010173302013000400009\&lng=pt\&nrm=iso $>$. ISSN 01017330. http://dx.doi.org/10.1590/S0101-73302013000400009.

LAGO MARTINEZ, S. La inclución digital y la educación em el Programa Conectar Igualdad. In: Educação (Porto Alegre), v.38, n.3, p.340-348, set-dez, 2015. Doi: http://dx.doi.org/10.15448/1981-2582.2015.3.21778 
DOI: $10.12957 /$ e-mosaicos.2018.27928

LIAW, S. Investigating student's perceveid satisfaction, behavioral intention, and effectiveness of e-learning: a case study of the Blackboard system. In: Computers \& Education. v.51, n. 2, 2008, p. 864-873.

MELO, A S.; ROCHA, H. G. B.; MERCADO, L. P. L. Utilização didática de objetos digitais de aprendizagem. In: Eccos Revista Científica. v. 10, n.1, 2008.

MIZUKAMI, M. G. N. Ensino: as abordagens do processo. São Paulo: EPU, 1986.

MORAN, J. M. Ensino e aprendizagem inovadores com tecnologias. Informática na Educação: Teoria \& Prática. v.3, n01, set 2000.

MORAN, J. M. Como utilizar as tecnologias na escola. In: $A$ educação que desejamos. Novos desafios e como chegar lá. 4ed. Papirus, 2009, p.101-111.

OLIVEIRA, E. S. G.; REGO, M. C. L. C.; VILLARDI, R. M. Aprendizage mediada por ferramentas de interação: análise do discurso de professores em um curso de formação continuada à distância. In: Educação \& Sociedade. v.28, n.101, 2007, p. 1413-1434. Doi: http://dx.doi.org/10.1590/S0101-73302007000400008.

PASTORE, J.; SILVA, N. V. Mobilidade social no Brasil. São Paulo: Makron Books, 2000.

PESCE, L.; BRUNO, A. R. Educação e inclusão digital: consistências e fragilidades no empoderamento dos grupos sociais. Educação (Porto Alegre), v.38, n.3, p.349-357, set-dez, 2015. Doi: http://dx.doi.org/10.15448/1981-2582.2015.3.21779

RAIJA, H.; PAIVI, H. Teacher's instructional planning for computer-supported collaborative learning: macro=scripts as a pedagogical method to facilitate collaborative learning. Teaching and Teacher Education. v.26, n.4, 2010, p. 871-877.

RAUH, J. Online education as a toll good: an examination of the South Carolina virtual school program. In: Computers \& Education. v.57, n.2, 2011, p. 1583-1594.

SAMSUDIN, K.; RAFI, A.; HANIF, A. S. Training in mental rotation and spatial visualization and its impact on orthographic drawing performance. In: Educational Technology \& Society. v.14, n. 1, jan 2011.

SANTAELLA, L. O papel do lúdico na aprendizagem. In: Revista Teias, v.13, no 30 , 185-195, set-dez 2012.

SILVA, M. Educar a geração pós-moderna. In: MAFRA, L.; TURA, M. (Orgs.) Sociologia para educadores 2: o debate sociológico da educação no século XXI e as perspectivas atuais. Rio de Janeiro: Quartet, 2005. 
DOI: $10.12957 /$ e-mosaicos.2018.27928

SILVA, C. M. T.; AZEVEDO, N. S. N. O significado das tecnologias de informação para educadores. In: Ensaio: Aval. pol. públ. educ. v.13, n.46. Rio de Janeiro, jan/mar, 2005.

SULTAN, W. H.; WOODS, P. C.; KOO, A. A constructivist approach for digital learning: Malaysian schools case study. In: Educational Technology \& Society. v.14, n.4, 2011.

THIOLLENT, M. Crítica metodológica, investigação social e enquete operária. São Paulo: Polis, 1980.

TURVEY, K. Pedagogical-research designs to capture the symbiotic nature of professional knowledge and learning about e-learning in initial teacher education in the UK. In: Computer \& Education, v.54, n.3, 2010, p. 783-790.

VIANNA, J. A Educação à distância, inclusão e mobilidade social. In: Interscienceplace, Ano 2 - nº 06, mar 2009.

XU, Y.; PARK, H.; BAEK, Y. A new approach toward digital storytelling: an ativity focused on writing self-efficacy in a virtual learning environment. In: Educational Technology \& Society. v.14, n.4, oct 2011.

Recebido em 10 de março de 2017 Aceito em 20 de julho de 2017 